\title{
WAKTU RESPON SENSOR GAS LPG DARI KOMPOSIT $\mathrm{CuO}\left(\mathrm{TiO}_{2}\right)$
}

\author{
Elvaswer \\ Jurusan Fisika FMIPA Universitas Andalas \\ Kampus Unand, Limau Manis, Padang, 25163 \\ elvaswer@fmipa.unand.ac.id,
}

\begin{abstract}
ABSTRAK
Telah dilakukan penelitian dari bahan komposit semikonduktor $\mathrm{TiO}_{2}(\mathrm{CuO})$ berupa pelet untuk karakterisasi sensor LPG (Liquefied Petroleum Gas) dengan metode solid state reaction. Pelet sensor LPG dibuat dengan bahan semikonduktor $\mathrm{CuO} 90 \%+\mathrm{TiO}_{2} 10 \%$. dengan proses pencampuran bahan, kalsinasi, penggerusan, kompaksi dan sintering. Proses kalsinasi pada temperatur $500^{\circ} \mathrm{C}$ selama 4 jam dan sintering pada $700^{\circ} \mathrm{C}$ selama 4 jam. Sensor LPG diuji pada temperatur ruang $\left(27^{\circ} \mathrm{C}\right)$ dengan melihat karakteristik waktu respon. Waktu respon pada sampel $\mathrm{CuO} 90 \%+\mathrm{TiO}_{2} 10 \%$ yaitu $50 \mathrm{~s}$.
\end{abstract}

Kata kunci : Komposit, $\mathrm{TiO} 2(\mathrm{CuO})$, sensor LPG, metode solid state reaction,, waktu respon.

\begin{abstract}
Research from the composite of semiconductor $\mathrm{TiO}_{2}(\mathrm{CuO})$ in the form of pellet for charachterizaton of LPG (Liquefied Petroleum Gas) sensor with method of solid state reaction. The pellet of LPG sensor of $\mathrm{CuO} 90 \%+\mathrm{TiO}_{2} 10 \%$ with the mixed of material, calcination, blended, compacted and sintered. Process of calcination at $500^{\circ} \mathrm{C}$ for 4 hours and sintered at $700^{\circ} \mathrm{C}$ for 4 hours. LPG sensor was investigated at room temperature $\left(27^{\circ} \mathrm{C}\right)$ with observed charachterization of rensponse time. Response time in sample $\mathrm{CuO} 90 \%+\mathrm{TiO}_{2} 10 \%$. is $50 \mathrm{~s}$.
\end{abstract}

Keyword : $\quad$ Composite, $\mathrm{TiO}_{2}(\mathrm{CuO})$, LPG sensor, method of solid state reaction, charachterization, response time.

\section{PENDAHULUAN}

Konversi bahan bakar minyak tanah ke gas LPG mempunyai prospek karena LPG lebih efisien dibandingkan minyak tanah dan biaya untuk LPG relatif lebih murah (Oktorizal, 2010). Untuk itu diperlukan sensor gas LPG untuk mendeteksi kebocoran dan menghindari ledakan. Sensor ini juga memiliki kelebihan lain yaitu biaya yang murah dan dapat diproduksi dalam jumlah yang banyak dibandingkan dengan sensor elektrokimia dan optik yang harganya mahal (Hendri, 2012).

Sensor gas semikonduktor pada umumnya dikenal sebagai sensor gas logam oksida karena terbuat dari bahan logam oksida seperti $\mathrm{TiO}_{2}, \mathrm{ZnO}, \mathrm{CuO}, \mathrm{SnO}_{2}$ dan sebagainya (Nopriyanti, 2012). Bahan semikonduktor ini dapat mendeteksi berbagai gas karena bahan oksida yang bereaksi dengan gas dapat merubah stoikiometri butiran bahan oksida tersebut jika menyerap ion-ion gas. Perubahan stoikiometri bahan tersebut akan mengakibatkan perubahan konduktivitas bahan semikonduktor (Akbar, 1997). 
Titanium dioksida $\left(\mathrm{TiO}_{2}\right)$ merupakan bahan logam oksida yang banyak digunakan dalam bebagai aplikasi gas sensor karena memiliki sifat fisik seperti permukaan kimia, transfer muatan dan sifat listrik yang baik (Yadav, dkk., 2011). Pemberian bahan logam mulia atau bahan logam oksida sebagai pendoping dapat meningkatkan kemampuan sensor gas. Akan tetapi, menggunakan bahan logam mulia membutuhkan biaya yang lebih mahal dan cukup sulit untuk diperoleh dibandingkan bahan logam oksida. Oleh karena itu, material $\mathrm{CuO}$ yang merupakan baham logam oksida digunakan sebagai bahan yang didoping. Material $\mathrm{CuO}$ memiliki sifat serapan (absorption) gas yang baik dan sifat kimia yang cocok untuk aplikasi katalis dan sensor gas (Wismadi, 2001).

\section{METODE PENELITIAN}

Bahan- bahan yang digunakan adalah Titanium dioxide $\left(\mathrm{TiO}_{2}\right)$ Merck Jerman dengan kemurnian 99,99\% dan Cupper Oxide (CuO) Merck Jerman dengan kemurnian 99,99\%. Ukuran sampel pelet yang diuji berdiameter $12 \mathrm{~mm}$ dan tebal pelet $2 \mathrm{~mm}$. Bahan sampel digerus selama kurang lebih dua jam hingga homogen, kalsinasi pada suhu $500^{\circ} \mathrm{C}$ selama 4 jam.. Selanjutnya bahan dikompaksi sehingga berbentuk pelet. Setelah itu, pelet di sintering pada suhu $700^{\circ} \mathrm{C}$ selama empat jam. Pengukuran dilakukan pada udara kemudian diteruskan dalam gas LPG.

Pengukuran waktu respon dilakukan 1 (satu) menit diudara dengan mengukur arus di lingkungan udara dan untuk 1 (satu) menit selanjutnya diberikan gas LPG dengan mengukur arus di lingkungan LPG. Pengukuran dilakukan setiap $5 \mathrm{~s}$. Rentang waktu antara arus diudara mengalami kenaikan saat diberikan LPG sampai arus di LPG menurun merupakan nilai waktu respon.

\section{HASIL DAN DISKUSIJN}

Pengukuran waktu respon pada sampel $90 \% \mathrm{CuO}+10 \% \mathrm{TiO}_{2}$ pad tegangan 30 volt. Pengukuran waktu respon pada sebuah sensor digunakan untuk mengetahui kemampuan sensor gas dalam mendeteksi gas di sekitarnya. Waktu respon yang dimiliki oleh sampel dapat ditunjukkan seperti pada Gambar 3.1.

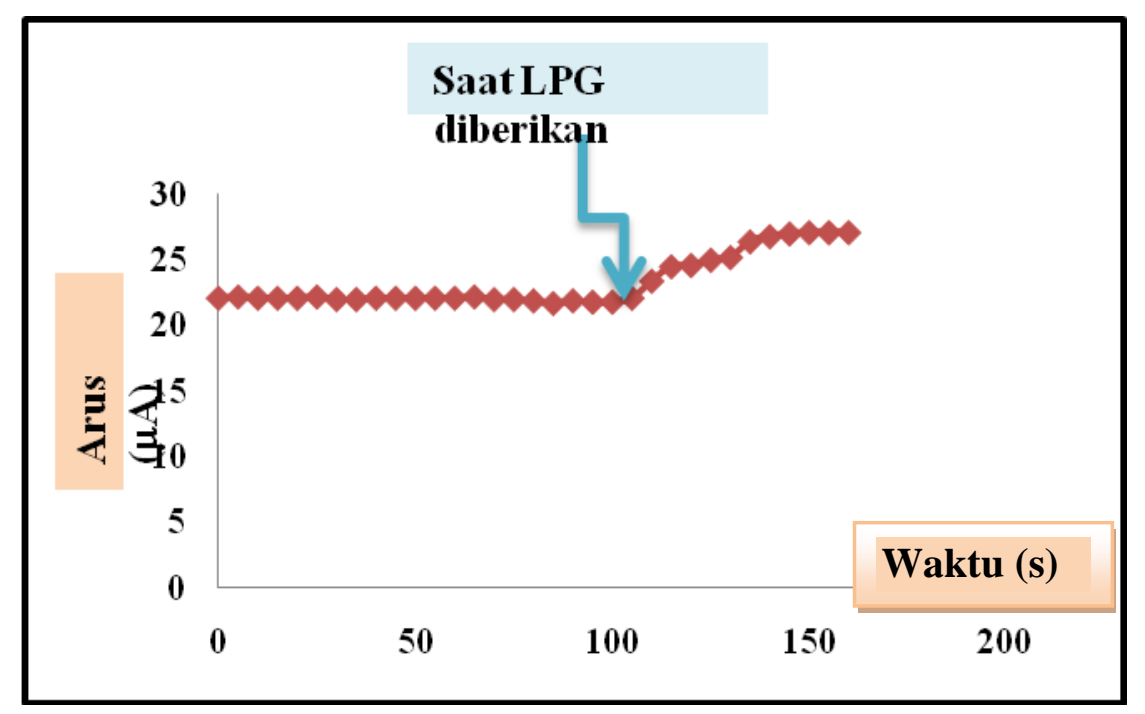

Gambar 3.1 Waktu respon sampel $90 \% \mathrm{CuO}+10 \% \mathrm{TiO}_{2}$ pada tegangan 30 volt 
Pengukuran waktu respon pada sampel dilakukan tiap 5s selama 100s di udara. Setelah dilakukan di udara, dilanjutkan dengan pemberian gas LPG dengan cara yang sama seperti yang dilakukan di udara sampai didapatkan arus konstan dengan waktu respon didapatkan 10s. Terjadinya peningkatan arus saat gas LPG dilalukan disebabkan gas LPG bereaksi dengan bahan sehingga dapat mengecilkan energi gap. Proses pengecilan energi gap sangat cepat yaitu dalam selang waktu 10s. Setelah 10s energi gap relative konstan sehingga arus menjadi relative konstan.

\section{KESIMPULAN}

Berdasarkan penelitian yang telah dilakukan terhadap semikonduktor $\mathrm{TiO}_{2}(\mathrm{CuO})$ sebagai sensor LPG dapat disimpulkan bahwa sensor mampu membedakan kondisi lingkungan udara dengan lingkungan LPG dengan waktu respon 50s.

\section{SARAN}

Disarankan mengunakan bahan doping yang berbeda untuk lebih menurunkan waktu respon. Mengunakan gas LPG dengan komposisi yang berbeda sehingga bisa menentukan sensitivitas pada gas LPG dengan konsentrasi rendah.

\section{DAFTAR PUSTAKA}

1. Akbar, A.S., 1997, Sensing Mechanism Of a Carbon Monoxide Sensor Based on Anatase Titania, Journal Electrochemistry Society, Vol 144 No.5

2. Hendri, 2012, Karakterisasi $\mathrm{TiO}_{2}(\mathrm{CuO})$ dengan Metoda Keadaan Padat (Solid State Reaction) sebagai Sensor Gas $\mathrm{CO}_{2}$, Skripsi, Program Studi S-1 Fisika, Fakultas Matematika dan Ilmu Pengetahuan Alam, Universitas Andalas, Padang.

3. Nopriyanti, R., 2012, Sintesis Lapisan Tipis $\mathrm{SnO}_{2}$ dalam Aplikasinya sebagai Sensor Gas CO dan Pengujian Sensitivitas, Universitas Pendidikan Indonesia, Bandung.

4. Oktorizal, A., 2010, Studi Sensor Gas Berbasis Surface Acoustic Wave Untuk Penerapan pada Sistem Identifikasi Gas, Universitas Andalas, Padang.

5. Wismadi, T., 2001, Pembuatan dan Karakterisasi Lapisan Tipis Copper Oxide $(\mathrm{CuO})$ Sebagai Sensor Gas, Institut Pertanian Bogor, Bogor.

6. Yadav, B. C., dkk, 2011, Solid-state Titania-based Gas Sensor for Liquefied Petroleum Gas Detection at Room Temperature, Bull. Mater. Sci., Vol. 34, No. 7, hal. 1639-1644. 